\title{
Reference Intervals for Thyroid Hormones During the First Trimester of Gestation: A Report from an Area with a Sufficient lodine Level
}

\section{Authors}

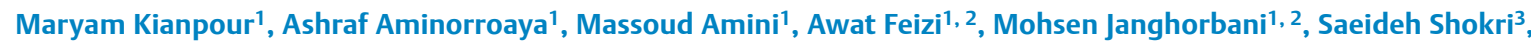
Sima Aminorroaya Yamini ${ }^{4}$, Maryam Farghadani ${ }^{3}$, Ali Hekmatnia ${ }^{3}$, Hossien Gharib ${ }^{5}$

\section{Affiliations}

1 Isfahan Endocrine and Metabolism Research Center, School of Medicine, Isfahan University of Medical Sciences, Isfahan, Iran

2 Department of Biostatistics \& Epidemiology, School of Public Health, Isfahan University of Medical Sciences, Isfahan, Iran

3 Department of Radiology, School of Medicine, Isfahan University of Medical Sciences, Isfahan, Iran

4 Department of Engineering and Mathematics, Sheffield Hallam University, Sheffield, UK

5 Mayo Clinic College of Medicine, Rochester, Minnesota, USA

\section{Key words}

pregnancy, first trimester, gestation, thyroid function test, TPOAb, TSH, reference interval, multiples of the median (MoM)

\section{received $\quad 09.10 .2018$}

accepted 05.02.2019

Bibliography

DOI https://doi.org/10.1055/a-0855-7128

Horm Metab Res 2019; 51: 165-171

(c) Georg Thieme Verlag KG Stuttgart · New York

ISSN 0018-5043

Correspondence

Ashraf Aminorroaya

Isfahan Endocrine and Metabolism Research Center

Isfahan University of Medical Sciences

Khorram Street

Isfahan

Iran

Tel.: + 98/31/33359 933, Fax: + 98/31/33373733

aminorroaya@med.mui.ac.ir

\section{ABSTRACT}

The physiological changes during pregnancy modulate the endocrine system. Therefore, both the American and the European thyroid associations recommend the use of local trimester-specific reference intervals. The purpose of this study was to establish the first trimester reference intervals for thyroid function tests in the central area of Iran. We examined 436 pregnant women in their first trimester of pregnancy, and 444 non-pregnant women in a cross sectional study. Serum levels of thyroid stimulating hormone (TSH), free thyroxin $\left(\mathrm{FT}_{4}\right)$, free triiodothyronine $\left(\mathrm{FT}_{3}\right)$, thyroid peroxidase antibody, urinary iodine concentration (UIC), and thyroid volume were measured for all subjects. The first trimester-specific reference intervals (2.5th-97.5th percentile) were determined for 185 pregnant women and 256 non-pregnant women with negative TPOAb, adequate iodine level $(\mathrm{UIC} \geq 150 \mu \mathrm{g} / \mathrm{l}$ in pregnant and $U I C \geq 100 \mu \mathrm{g} / \mathrm{l}$ in non-pregnant women), and normal thyroid examination. We calculated multiples of the median (MoM) for TFTs to normalize the obtained data. The first trimester-specific reference intervals of serum $\mathrm{TSH}_{1} \mathrm{FT}_{4}$, and $\mathrm{FT}_{3}$ for pregnant women were $0.20-4.60 \mathrm{mIU} / \mathrm{l}, 9.0-18.02 \mathrm{pmol} / \mathrm{l}$, and 3.40-5.64 pmol/l, respectively, while the corresponding figures for non-pregnant women were $0.59-5.60 \mathrm{mIU} / \mathrm{l}$, 9.52$19.30 \mathrm{pmol} / \mathrm{l}$, and $3.70-5.55 \mathrm{pmol} / \mathrm{l}$, respectively. The first and 99th percentile MoM of TSH in pregnant women in their first-trimester was 0.026-4.61. The local normal reference ranges for the first trimester of pregnancy in central region of Iran were different from the ranges suggested by the ATA. 


$\begin{array}{ll}\text { ABBREVIATIONS } \\ \text { TFTs } & \text { Thyroid function tests } \\ \text { TSH } & \text { Thyroid stimulating hormone } \\ \text { FT }_{4} & \text { Free thyroxin } \\ \text { FT3 } & \text { Free triiodothyronine } \\ \text { TPOAb } & \text { Thyroid peroxidase antibody } \\ \text { UIC } & \text { Urinary iodine concentration } \\ \text { HCG } & \text { Human chorionic gonadotropin } \\ \text { TBG } & \text { Thyroid-binding globulin } \\ \text { ATA } & \text { American Thyroid Association } \\ \text { LMP } & \text { The first day of the last menstrual period } \\ \text { MoM } & \text { Multiples of the median } \\ \text { SD } & \text { Standard Deviation } \\ \text { NACB } & \text { National Academy of Clinical Biochemistry } \\ \text { NHANES } & \text { National Health and National Examination Survey }\end{array}$

\section{Background}

Pregnancy makes dynamic changes in several systems in the body, including the thyroid [1], mainly affected by the thyroid stimulating effect of human chorionic gonadotropin (HCG), secreted from placental syncytiotrophoblast, which has structural similarity with thyroid stimulating hormone (TSH) [2-4]. The highest concentration of $\beta$-HCG is observed in the first trimester of pregnancy, when thyrotropine decreases [3] and the concentration of serum thyroid-binding globulin (TBG) rises due to high levels of maternal estradiol $\left(E_{2}\right)$ [5]. Furthermore, the maternal iodine requirement increases as a result of higher renal clearance of this essential element and fetal use of iodine [6].

The importance of maternal thyroid malfunction on pregnancy and fetal development is well known, with potential adverse prenatal outcomes, such as miscarriage, pre-eclampsia, placental abruption, preterm birth, post-partum hemorrhage, low birth weight, increased neonatal respiratory distress syndrome, and decreased cognitive function [6,7]. Many factors such as iodine intake $[8,9]$, ethnicity, gestational age $[10,11]$, laboratory assay methods [12], the study design method, and selection of the reference population $[13,14]$ can affect the reference ranges of thyroid function tests (TFTs) and lead to inconsistent reported values. Due to the diversity exists in TSH concentrations during pregnancy, the guidelines of the Endocrine Society, the American Thyroid Association (ATA), and the European Thyroid Association (ETA) recommend that trimester-specific reference ranges should be established and used for each region separately [15-17].

Due to limited data available for the trimester-specific reference intervals in Iranian pregnant women, we conducted this study to establish specific reference ranges for thyroid function tests in healthy pregnant women during their first trimester of gestation at the central area of Iran. We have also calculated the multiple of the median (MoM) values [18].

\section{Subjects and Methods}

In this cross sectional study, 880 women, who were referred to antenatal care clinics for mother and child health care, and private clin- ics for the first prenatal care visit, were enrolled from September 2015 to January 2017. The samples were selected from 25 urban health centers affiliated to the Isfahan University of Medical Science and 30 private gynecology and midwifery clinics in different areas of the city. In order to obtain a representative sample group, we randomly selected health centers and private clinics; this was followed by random selection of women from the list of eligible participants in each center and clinic. In each included center or clinic in our study, a pair matching was performed between pregnant and non-pregnant women based on age and gravida; eventually 436 pregnant and 444 non-pregnant women were enrolled in the study.

Women aged 15-45 were included in the study and the gestational age was calculated based on the first day of their last menstrual period (LMP); if the woman was unsure about her LMP, the ultrasound report was considered as the beginning of pregnancy to the completion of 14th week of gestation [19]. We excluded women with multiple gestation, goiter or thyroid nodules, autoimmune, acute or chronic diseases, positive thyroid peroxidase antibody, and known thyroid disease. Women who were taking levothyroxine, propylthiouracil, methimazole, or any other medications, which could affect TFTs were excluded from the study. Pregnant women with UIC less than $150 \mu \mathrm{g} / \mathrm{I}$ and non-pregnant women with UIC less than $100 \mu \mathrm{g} / \mathrm{I}$ were also excluded from the study (233 pregnant and 188 non-pregnant women). Finally, the reference ranges were determined for 185 pregnant and 256 non-pregnant women. For the flow chart of the study design, $>$ Fig. 1.

Each woman was visited individually and signed the informed consent form after receiving complete verbal explanation about the study objectives.

Five milliliter venous blood sample was obtained from each participant, centrifuged and the serum was stored at $-70{ }^{\circ} \mathrm{C}$ for 2 days. Serum concentrations of TSH, free thyroxin $\left(\mathrm{FT}_{4}\right)$, free triiodothyronine $\left(\mathrm{FT}_{3}\right)$, and TPOAb were measured in the laboratory of Isfahan Endocrine and Metabolism Research Center of Isfahan University of Medical Sciences. Urine samples were collected and frozen in falcon tubes and transmitted to Isfahan Health Center Laboratory to measure the urinary iodine concentration. Urinary iodine concentration was measured by chloric acid digestion method [20]. All samples were taken within 7:30-10:30 AM. Thyroid volume was measured using ultrasound scanning by Philips affinity 70 , superficial probe, 4-12 MHz (Made in the Netherlands), for all women by an expert sonographer (S.Sh.). The volume of each lobe $(\mathrm{ml})$ was calculated by $0.000479 \times$ length $\times$ width $\times$ thickness $(\mathrm{mm})$. TPOAb values higher than $60 \mathrm{IU} / \mathrm{ml}$ were considered as positive according to the manufacturer's cut-off values.

Serum concentrations of $\mathrm{TSH}_{1} \mathrm{FT}_{4}, \mathrm{FT}_{3}$, and TPOAb were measured by chemiluminescence immunoassay sys-ADVIA centaur CP/ SIMENS 2010-American. TSH Intra-assay and inter-assay coefficient of variation (CV) were $2.8-3.1 \%$ and $2.9-3.5 \%$, respectively. $\mathrm{FT}_{4}$ intra-assay was $1.68-2.22 \%$ and interassay $C V$ was $1.42 \%$ and $3.48 \%$; the intra-assay and interassay $\mathrm{CV}$ for $\mathrm{FT}_{3}$ were $1.7-4.0 \%$ and $3.1-3.4 \%$, respectively. The intra-assay and interassay CV values for TPO-Ab were $1.7-7.8 \%$ and $2.0-7.3 \%$, respectively.

The ethics committee of the Isfahan University of Medical Sciences approved the design and protocol of the present study and all steps were aligned with the principles of Declaration of Helsinki on human studies. 


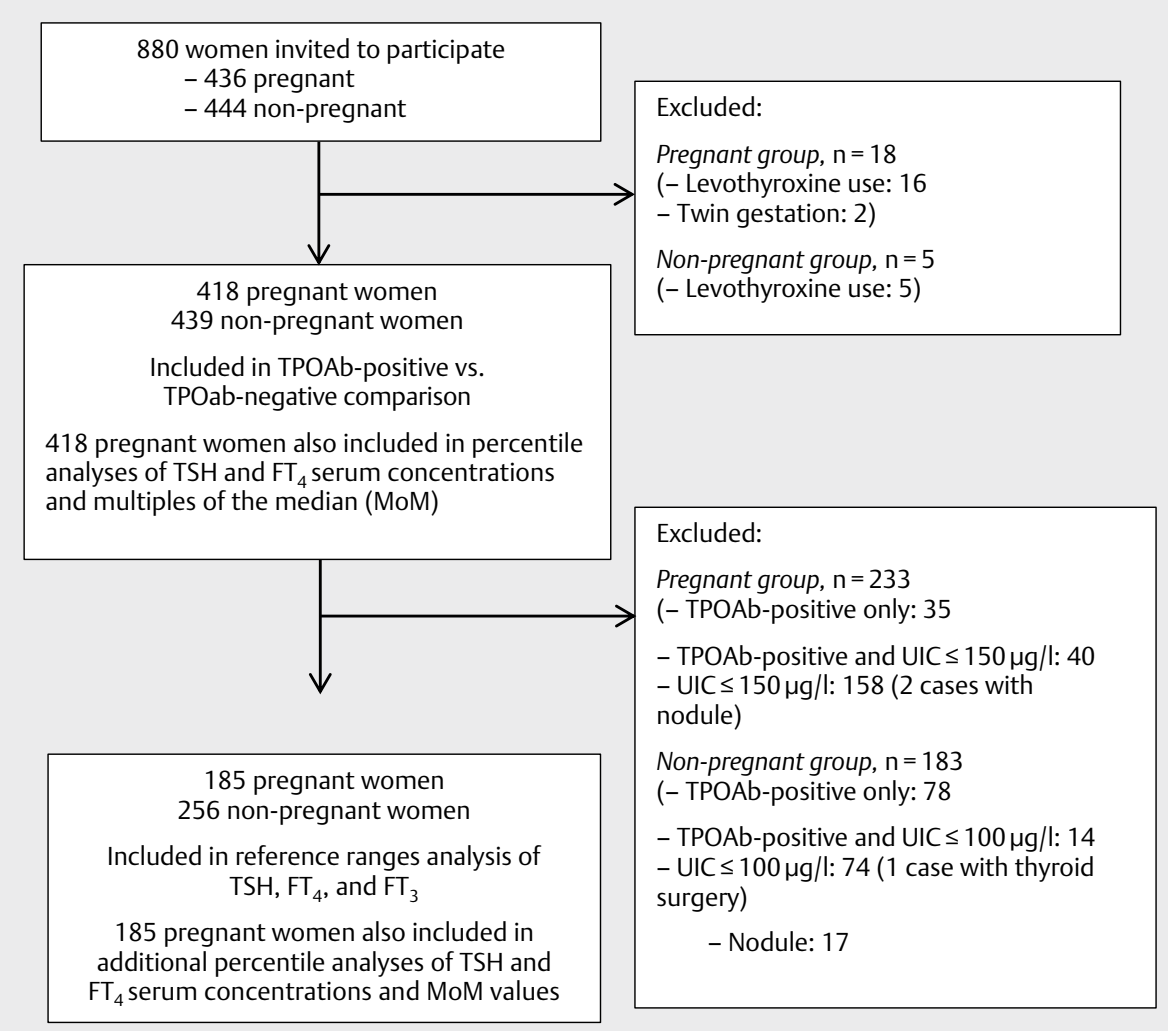

- Fig. 1 Flow chart of the study design.

\section{Statistical analysis}

The data were statistically analyzed using Statistical Package for Social Science (SPSS), version 16.0 (IBM statistic software, 2009, NY; USA). The results of TFT were examined for normality by Kolmogorov-Smirnov test and Q-Q plot. Positive skewed data were subjected to logarithmic and square root transformations. The data with normal distribution were reported by mean and standard deviation (SD). In pregnant women, the distribution of square root for TSH, log base 10 for $\mathrm{FT}_{3}$ and $\mathrm{Ln}$ (le Logarithme Naturel) for $\mathrm{FT}_{4}$ were used for approximation of Gaussian normality, while in non-pregnant women Ln approximation was used for $\mathrm{TSH}_{1} \mathrm{FT}_{4}$, and $\mathrm{FT}_{3}$.

The manufacturer's values were as follows: TSH: $0.35-5.50 \mathrm{mlU} / \mathrm{l}$, $\mathrm{FT}_{4}$ : 11.45-22.65 pmol/l, and $\mathrm{FT}_{3}: 3.1-6.5 \mathrm{pmol} / \mathrm{I}$. For each TFT, median, 2.5th, 5th, 10th, 90th, 95th, 97.5th percentile, first and third quartiles were calculated. The 2.5 th and 97.5 th percentiles were determined as limits of the reference ranges. Comparisons between different groups were performed using Student's t-test and Chisquare test, where appropriate. Median test and binomial test were used to compare differences in median and selected percentiles between pregnant and non-pregnant women. p-Values less than 0.05 were considered statistically significant.

We have also calculated multiples of medians (MoMs) for TSH and $\mathrm{FT}_{4}$. MoMs have been calculated by dividing the results of TFTs by the median value of each test in that population [18].

\section{Results}

The mean \pm SD of age for 185 pregnant and 256 non-pregnant women was $28.7 \pm 5.11$ and $29.3 \pm 4.87$ years, respectively $(p=0.21)$. Median, minimum, and maximum gravida in pregnant and non-pregnant women were 2,1 , and 6 , respectively. More details about the basic and clinical characteristics of participants in both groups are presented in $>$ Table 1.

Reference ranges for $\mathrm{TSH}, \mathrm{FT}_{4}$ and $\mathrm{FT}_{3}$ values in the first trimester of gestation were $0.2-4.60 \mathrm{mIU} / \mathrm{l}, 9.0-18.02 \mathrm{pmol} / \mathrm{I}$, and 3.40$5.64 \mathrm{pmol} / \mathrm{l}$, respectively, and in non-pregnant women were 0.59 $5.60 \mathrm{mIU} / \mathrm{I}, 9.52-19.30 \mathrm{pmol} / \mathrm{l}$, and $3.70-5.55 \mathrm{pmol} / \mathrm{l}$, respectively.

The first quartile (25th percentile) of $\mathrm{TSH}, \mathrm{FT}_{4}$, and $\mathrm{FT}_{3}$ concentrations in pregnant women were $1.0 \mathrm{mIU} / \mathrm{l}, 11.60 \mathrm{pmol} / \mathrm{l}$ and $4.10 \mathrm{pmol} / \mathrm{l}$, respectively, and the corresponding figures for non-pregnant women were $1.40 \mathrm{mIU} / \mathrm{l}, 12.87 \mathrm{pmol} / \mathrm{l}$, and $4.20 \mathrm{pmol} / \mathrm{l}$, respectively, and the third quartile (75th percentile) of $\mathrm{TSH} \mathrm{FT}_{4}$, and $\mathrm{FT}_{3}$ concentrations were $2.10 \mathrm{mlU} / \mathrm{l}, 14.15 \mathrm{pmol} / \mathrm{l}$, and $4.70 \mathrm{pmol} / \mathrm{l}$, respectively, in pregnant women, and $2.90 \mathrm{mIU} / \mathrm{l}, 15.44 \mathrm{pmol} / \mathrm{l}$, and $4.70 \mathrm{pmol} / \mathrm{I}$ in non-pregnant women.

TPOAb was positive in $17.9 \%$ of pregnant (75/418) and $21.9 \%$ of non-pregnant (96/438) women; comparing the TFTs between participants with positive and negative TPOAb indicated that pregnant women with positive TPOAb had a higher median and 97.5th percentiles of TSH than pregnant women with negative TPOAb. The same results were obtained for non-pregnant women ( $>$ Table 2 ). 
- Table 1 Participants' basic characteristics and thyroid hormone levels.

\begin{tabular}{|c|c|c|c|}
\hline Variables & $\begin{array}{l}\text { Pregnant women } \\
(n=185)\end{array}$ & $\begin{array}{l}\text { Non-pregnant women } \\
(n=256)\end{array}$ & p-Value \\
\hline Age (years) ${ }^{*}$ & $28.7 \pm 5.11$ & $29.3 \pm 4.87$ & 0.212 \\
\hline \multicolumn{4}{|l|}{ TSH Median (2.5th-97.5th) (mIU/l) ${ }^{* *}$} \\
\hline Age $<25$ years & $1.6(0.3-4.1)$ & $1.9(0.71-5.8)$ & \\
\hline Age $25-29.99$ years & $1.35(0.2-4.6)$ & $2.1(0.6-7.8)$ & \\
\hline Age $30-34.99$ years & $1.6(0.13-5.22)$ & $1.95(0.5-4.8)$ & \\
\hline Age $\geq 35$ years & $1.5(0.2-4.9)$ & $2.1(0.8-4.5)$ & \\
\hline Gestational age (week/day) ${ }^{*}$ & $9.6 \pm 2.6$ & - & \\
\hline Gestational age (week/day) ${ }^{* *}$ & $10 w / 3 d(5 w-14 w / 1 d)$ & & \\
\hline Urinary iodine concentration (Min-Max) $(\mathrm{mg} / \mathrm{l})^{* * *}$ & $209.0(150-549)$ & $194.0(100-533($ & 0.135 \\
\hline Thyroid volume (ml)* & $6 . \pm 2.5^{*}$ & $6.4 \pm 2.1^{*}$ & 0.245 \\
\hline TSH Median (Min-Max) $(\mathrm{mlU} / \mathrm{l})^{* * *}$ & $1.50(0.03-5.30)$ & $2.10(0.5-9.7)$ & 0.001 \\
\hline 2.5th percentile of TSH & 0.20 & 0.59 & \\
\hline 5th percentile of TSH & 0.40 & 0.80 & \\
\hline 10th percentile of TSH & 0.60 & 1.00 & \\
\hline 90th percentile of TSH & 2.85 & 3.80 & \\
\hline 95th percentile of TSH & 4.10 & 4.30 & \\
\hline 97.5th percentile of TSH & 4.60 & 5.60 & \\
\hline $\mathrm{FT}_{4}$ Median (Min-Max) $(\mathrm{pmol} / \mathrm{ll})^{* * *}$ & $12.87(9.0-22.65)$ & $14.15(9.0-27.02)$ & 0.001 \\
\hline 2.5th percentile of $\mathrm{FT}_{4}$ & 9.0 & 9.52 & \\
\hline 5th percentile of $\mathrm{FT}_{4}$ & 10.30 & 10.30 & \\
\hline 10th percentile of $\mathrm{FT}_{4}$ & 11.58 & 11.60 & \\
\hline 90th percentile of $\mathrm{FT}_{4}$ & 15.44 & 18.01 & \\
\hline 95th percentile of $\mathrm{FT}_{4}$ & 16.73 & 18.01 & \\
\hline 97.5th percentile of $\mathrm{FT}_{4}$ & 18.02 & 19.30 & \\
\hline $\mathrm{FT}_{3}$ Median (Min-Max) $(\mathrm{pmol} / \mathrm{ll})^{* * *}$ & $4.40(2.50-6.90)$ & $4.50(2.70-7.50)$ & 0.356 \\
\hline 2.5th percentile of $\mathrm{FT}_{3}$ & 3.40 & 3.70 & \\
\hline 5th percentile of $\mathrm{FT}_{3}$ & 3.53 & 3.80 & \\
\hline 10th percentile of $\mathrm{FT}_{3}$ & 3.80 & 3.90 & \\
\hline 90th percentile of $\mathrm{FT}_{3}$ & 5.10 & 5.10 & \\
\hline 95th percentile of $\mathrm{FT}_{3}$ & 5.27 & 5.20 & \\
\hline 97.5th percentile of $\mathrm{FT}_{3}$ & 5.64 & 5.55 & \\
\hline
\end{tabular}

MoM values for different percentiles of serum $\mathrm{TSH}_{\mathrm{H}}$ and $\mathrm{FT}_{4}$ in pregnant women are summarized in $>$ Table 3.1 and $>$ Table 3.2; MoM values of 1 st and 99th percentiles for TSH were 0.026 and 4.61 in total sample and in healthy pregnant women were 0.05 and 3.41. MoM values for $\mathrm{FT}_{4}$ at the 2.5th and 99th percentiles were 0.70 and 1.40 in total sample and in healthy pregnant women were 0.70 and 1.45 , respectively.

\section{Discussion}

In the present study, we measured concentrations of TSH, $\mathrm{FT}_{4}, \mathrm{FT}_{3}$, and TPOAb in pregnant women during their first trimester and compared the results with a non-pregnant control group to determine the first trimester reference range of TFTs. A longitudinal and cross-sectional study from China [13] measured TSH concentration in pregnant women with negative TPOAb during their first trimester of gestation. Our results for the 2.5th percentile of TSH in pregnant women with negative TPOAb was similar to their values in the cross-sectional study $(0.2 \mathrm{mIU} / \mathrm{l}$ vs. $0.19 \mathrm{mIU} / \mathrm{I}$ for cross sectional and $0.02 \mathrm{mIU} / \mathrm{I}$ for longitudinal studies), while the 97.5 th percentile of TSH concentration in our study was higher than their similar percentile in both longitudinal and cross sectional studies ( $4.60 \mathrm{mIU} / \mathrm{l}$ vs. $3.54 \mathrm{mIU} / \mathrm{I}$ for cross sectional and $3.65 \mathrm{mIU} / \mathrm{l}$ for longitudinal studies).

Previous studies reported the 2.5th and 97.5th percentiles of TSH in Brazilian [21], Swiss [22] and Indian [23] pregnant women during the first trimester as $0.14-3.68 \mathrm{mIU} / \mathrm{l}, 0.0878-2.829 \mathrm{mIU} / \mathrm{l}$, 
- Table 2 Median and $2.5^{\text {th }}$ and $97.5^{\text {th }}$ percentiles of thyroid function test values for participants with positive and negative thyroid peroxidase antibody (TPOAb) in both groups of pregnant and non-pregnant women, including women with and without iodine deficiency.

\begin{tabular}{|c|c|c|c|c|c|c|}
\hline \multirow[t]{2}{*}{ Variable } & \multicolumn{2}{|l|}{ Pregnant women } & \multirow[t]{2}{*}{$P$ value } & \multicolumn{2}{|c|}{ Non-pregnant women } & \multirow[t]{2}{*}{$P$ value } \\
\hline & TPOAb-positive $(n=75)$ & $\begin{array}{l}\text { TPOAb-negative } \\
(\mathrm{n}=343)\end{array}$ & & $\begin{array}{l}\text { TPOAb-positive } \\
(n=96)\end{array}$ & $\begin{array}{l}\text { TPOAb-negative } \\
(\mathrm{n}=343)\end{array}$ & \\
\hline \multicolumn{7}{|l|}{ TSH } \\
\hline Median (min-max) mIU/l & $1.70(0.001-9.80)$ & $1.50(0.01-7.10)$ & 0.049 & $3.05(0.006-113)$ & $\begin{array}{l}2.10(0.008- \\
10.70)\end{array}$ & 0.001 \\
\hline 2.5th percentile & 0.09 & 0.20 & & 0.24 & 0.50 & \\
\hline 97.5th percentile & 8.81 & 4.65 & & 23.54 & 5.74 & \\
\hline \multicolumn{7}{|l|}{ FT4 } \\
\hline $\begin{array}{l}\text { Median (min-max) } \\
\mathrm{pmol} / \mathrm{l}\end{array}$ & $12.8(9.009-28.31)$ & $\begin{array}{l}12.78(9.009- \\
22.56)\end{array}$ & 0.03 & $\begin{array}{l}14.16(5.15- \\
24.50)\end{array}$ & $\begin{array}{l}14.16(9.009- \\
33.50)\end{array}$ & 0.069 \\
\hline 2.5th percentile & 9.009 & 9.009 & & 7.46 & 10.30 & \\
\hline 97.5th percentile & 19.303 & 16.73 & & 18.14 & 19.30 & \\
\hline \multicolumn{7}{|l|}{ FT3 } \\
\hline $\begin{array}{l}\text { Median (min-max) } \\
\mathrm{pmol} / \mathrm{l}\end{array}$ & $4.50(3.50-10.50)$ & $4.50(2.30-6.90)$ & 0.232 & $4.40(2.20-7.70)$ & $4.50(2.70-9.80)$ & 0.023 \\
\hline 2.5th percentile & 3.59 & 3.46 & & 3.00 & 3.70 & \\
\hline 97.5th percentile & 6.18 & 5.90 & & 5.25 & 5.54 & \\
\hline
\end{tabular}

- Table 3.1 The serum TSH concentrations and multiples of the median (MoM) values at various percentiles in pregnant women $(\mathrm{n}=418)$, and in the healthy pregnant women (TPOAb-negative and urinary iodine concentration [UIC] $>150 \mu \mathrm{g} / \mathrm{l} ; \mathrm{n}=185$ ) whose data were used to determine the reference range.

\begin{tabular}{|c|c|c|c|c|}
\hline \multirow[t]{2}{*}{$\begin{array}{l}\text { Percen- } \\
\text { tile }\end{array}$} & \multicolumn{2}{|c|}{$\begin{array}{l}\text { Pregnant group } \\
{ }^{* *} \mathrm{n}=\mathbf{4 1 8}\end{array}$} & \multicolumn{2}{|c|}{$\begin{array}{l}\text { Healthy pregnant } \\
\text { group } n=185\end{array}$} \\
\hline & $\mathrm{TSH}(\mathrm{mlU} / \mathrm{I})$ & $\begin{array}{l}\text { MoM } \\
\text { TSH }\end{array}$ & $\mathrm{TSH}(\mathrm{mIU} / \mathrm{I})$ & $\begin{array}{l}\text { MoM } \\
\text { TSH }\end{array}$ \\
\hline $1 \mathrm{st}$ & 0.04 & 0.026 & 0.081 & 0.05 \\
\hline $2 \mathrm{nd}^{*}$ & - & - & - & - \\
\hline 2.5th & 0.20 & 0.133 & 0.20 & 0.133 \\
\hline 5th & 0.30 & 0.20 & 0.40 & 0.266 \\
\hline 10th & 0.50 & 0.33 & 0.60 & 0.40 \\
\hline 50th & 1.50 & 1.00 & 1.50 & 1 \\
\hline 90th & 3.40 & 2.26 & 2.85 & 1.89 \\
\hline 95th & 4.41 & 2.93 & 4.10 & 2.73 \\
\hline 97.5th & 5.10 & 3.40 & 4.60 & 3.06 \\
\hline 98th & 5.55 & 3.70 & 4.68 & 3.12 \\
\hline 99th & 6.91 & 4.61 & 5.13 & 3.41 \\
\hline \multicolumn{5}{|c|}{$\begin{array}{l}{ }^{*} \text { Available data did not permit assignment of values at these } \\
\text { percentiles. }{ }^{*} \text { Including those with TPOAb-positivity and/or UIC } \leq \\
150 \mu \mathrm{g} / \mathrm{l}\end{array}$} \\
\hline
\end{tabular}

Table 3.2 The serum $\mathrm{FT}_{4}$ concentrations and multiples of the median (MoM) values at various percentiles, in pregnant women $(\mathrm{n}=418)$, and in healthy pregnant women (TPOAb-negative and urinary iodine concentration $[\mathrm{UIC}]>150 \mu \mathrm{g} / \mathrm{l} ; \mathrm{n}=185$ ) whose data were used to determine the reference range.

\begin{tabular}{|c|c|c|c|c|}
\hline \multirow[t]{2}{*}{$\begin{array}{l}\text { Percen- } \\
\text { tile }\end{array}$} & \multicolumn{2}{|c|}{$\begin{array}{l}\text { Pregnant group * * } \\
(\mathrm{n}=418)\end{array}$} & \multicolumn{2}{|c|}{$\begin{array}{l}\text { Healthy pregnant } \\
\text { group }(n=185)\end{array}$} \\
\hline & $\mathrm{FT}_{4}(\mathrm{pmol} / \mathrm{I})$ & $\begin{array}{l}\text { MoM } \\
\mathrm{FT}_{4}\end{array}$ & $\mathrm{FT}_{4}(\mathrm{pmol} / \mathrm{l})$ & $\begin{array}{l}\mathrm{MoM} \\
\mathrm{FT}_{4}\end{array}$ \\
\hline $1 \mathrm{st} *$ & - & - & - & - \\
\hline $2 n d^{*}$ & - & - & - & - \\
\hline 2.5th & 9.00 & 0.70 & 9.00 & 0.70 \\
\hline 5 th $^{*}$ & - & - & 10.30 & 0.80 \\
\hline 10th & 10.30 & 0.80 & 11.58 & 0.90 \\
\hline 50th & 12.87 & 1.00 & 12.87 & 1.00 \\
\hline 90th & 15.44 & 1.20 & 15.44 & 1.20 \\
\hline 95th * & - & - & 16.73 & 1.30 \\
\hline 97.5th * & 16.73 & 1.30 & - & - \\
\hline 98th * & - & - & 18.02 & 1.40 \\
\hline 99th & 18.02 & 1.40 & 18.66 & 1.45 \\
\hline
\end{tabular}

${ }^{*}$ Available data did not permit assignment of values at these percentiles in one or both groups. ${ }^{*} *$ Including those with TPOAb-positivity and/or UIC $\leq 150 \mu \mathrm{g} / \mathrm{l}$. 
0.09-6.65 mIU/I, respectively. Another study [24] defined the 2.5th and 97.5th percentiles of TSH in pregnant women with negative TPOAb at 4-13 weeks of gestation at $0.06-8.3 \mathrm{mlU} / \mathrm{l}, 0.04-$ $9.3 \mathrm{mIU} / \mathrm{l}$, and 0.12-7.4 mIU/I in United Arab Emirates, other Arab nations, and Asians, respectively.

The results of a large multi-ethnicity population-based cohort study from the Netherlands [25] on Dutch, Turkish, Moroccan, and Surinamese pregnant women showed higher levels of TSH in Dutch women, although it was lower than our findings ( $0.11-4$.18 vs. $0.2-$ $4.60 \mathrm{mIU} / \mathrm{l})$.

The highest values for 2.5th and 97.5th percentiles of TSH concentration in pregnant women have been reported for Arab pregnant women residing in United Arab Emirates [24], and the lowest values have been reported for white Swiss women [22]. Evidence also suggests higher TSH concentration levels in the Middle Eastern and Asian pregnant women, compared to the European [22] and South American [21] pregnant women. These regional discrepancies might also originate from differences such as gestational age at sampling, ethnicity and racial differences of maternal HCG levels [26], genetic characteristics [14], study design [11], assay methods, iodine intake status [27], and inclusion criteria for the determination of reference population and sample size [28]. Our results show slight differences in the 5 th and 95 th percentile of TSH concentration with previous reports from Tehran, Iran $[29,30]$ (5th percentile: 0.4 vs. $0.2 \mathrm{mIU} / \mathrm{l}$ and 95 th percentile: $4.10 \mathrm{vs} .3 .9 \mathrm{mIU} / \mathrm{l})$. The similarity of our findings with previous reports $[29,30]$ from another large region in Iran, suggests that the same reference interval can be implemented for the first trimester of gestation in Iranian pregnant women.

In the present study, 2.5th and 97.5th percentiles of pregnant women with positive TPOAb were $0.190-8.830 \mathrm{mIU} / \mathrm{I}$, higher than that in pregnant women with negative TPOAb $0.01-7.10 \mathrm{mIU} / \mathrm{l}$, consistent with previous studies $[9,31]$. Women with positive TPOAb were treated by levothyroxine in Italy, which reduced the negative pregnancy outcomes [32], supporting the negative impact of positive TPOAb on pregnancy. This suggests that women with positive TPOAb should be excluded from the studies that aim to define the reference ranges for TSH concentration [27].

We have shown that the reference range of TSH concentration in the first trimester of pregnancy $(0.2-4.60 \mathrm{mIU} / \mathrm{I})$ for Iranian women was lower and narrower than manufacturer's reference values $(0.35-5.50 \mathrm{mIU} / \mathrm{I})$; the reference range derived for non-pregnant women was $0.59-5.60 \mathrm{mlU} / \mathrm{l}$.

The reference ranges of TFTs for pregnant and non-pregnant women are incomparable due to the physiological changes during pregnancy. The thyrotrophic effect of HCG is associated with lower serum TSH concentration, especially during early stage of pregnancy $[1,33]$. Therefore, the reference ranges for TSH and other TFTs of the general population should not be used to interpret the TFTs during pregnancy. Moreover, our TSH reference range (0.2$4.60 \mathrm{mIU} / \mathrm{I})$ is wider and higher than the ATA recommendation for Americans and Europeans in the first trimester of pregnancy (0.1$2.5 \mathrm{mIU} / \mathrm{I}$ ) in 2017 [15]. However, recent studies in Asia, India, and the Netherlands, have shown only a modest reduction in the upper reference limit [25, 34-37]. A study from China [35] showed a downward shift in the TSH reference range at 7-12 weeks of ges- tational age; the upper reference interval was decreased from 5.31 to $4.34 \mathrm{mIU} / \mathrm{l}$.

Previous report [15] showed that both the lower and upper limits of maternal TSH were reduced during pregnancy by about $0.1-$ $0.2 \mathrm{mIU} / \mathrm{l}$ and $0.5-1.0 \mathrm{mIU} / \mathrm{I}$ respectively, relative to the non-pregnant reference interval of TSH. According to the reference interval of TSH for non-pregnant women, derived from our study (0.59$5.60 \mathrm{mIU} / \mathrm{I})$, the lower and upper limits of reference interval for TSH should change to $0.39-0.49 \mathrm{mIU} / \mathrm{I}$, and $4.60-5.10 \mathrm{mIU} / \mathrm{I}$, respectively, for the first trimester of pregnancy in Iranian population.

In the present study, the 2.5th-97.5th percentile range for $\mathrm{FT}_{4}$ concentration was determined as 9.0-18.02 pmol/l, which was lower and narrower than that found for non-pregnant women (9.52-19.30 pmol/I) and manufacture's reference values (11.45$22.65 \mathrm{pmol} / \mathrm{l})$. Whereas, the calculated reference ranges for $\mathrm{FT}_{3}$ concentration in pregnant women (3.40-5.64 pmol/l) was marginally wider than that for non-pregnant women (3.70-5.55 pmol/l); and the reference ranges for $\mathrm{FT}_{3}$ concentration in pregnant and non-pregnant women were narrower than manufacturer's values (3.1-6.5 pmol/I). Factors such as exclusion criteria, population characteristics, immunometric assay method and iodine sufficiency status might have led to different values of such markers [38].

Previous studies [39-41] suggested the transformation of the results to multiples of median (MoM) in order to unitize different laboratories reports. This method is universally used for antenatal screening of Down syndrome and neural tube defects [41]. MoM is usually used for screening test results, specifically when the results of each test show considerable variations [42].

We reported MoM values of TSH and FT4 concentrations to overcome the effect of maternal weight and gestational age on the hormonal values. The 1st-99th percentiles of TSH MoM were $0.026-$ 4.61 and the 2.5th-99th percentiles of $\mathrm{FT}_{4}$ MoM were 0.70-1.40.

In the UK and Italian pregnant women with gestational ages less than 16 weeks, the lower and upper limit of TSH MoM (1st-99th percentiles) were $0.02-4.57$ and $0.01-4.10$, respectively, and their similar percentiles for free thyroxine MoM were $0.75-1.38$ and $0.76-1.46$, respectively [39]. A study from the USA [41] reported 97.5 th percentile of TSH concentration in the first trimester singleton and twin pregnancies as 4.0 and 3.5 MoM, respectively. Based on these results, the upper limit was defined as $2.5 \mathrm{MoM}$ in singleton and twin pregnancies [41]. Our results showed that the upper limit (99th percentile) for TSH concentration at 4.61 MoM covers approximately 96.5 percentile points of TSH concentration, during the first trimester of pregnancy (5th-14th weeks of pregnancy). According to our findings, the upper value for $\mathrm{FT}_{4} \mathrm{MoM}$ in pregnant women was 1.4, which can cover 99 percentile points of $\mathrm{FT}_{4}$ concentration in the pregnant population.

With regard to the national protocol of maternal care in Iran, TSH is measured in the first prenatal care visit. Based on manufacturer's recommended reference ranges, $7.89 \%$ of women could have been diagnosed with hypo- and hyperthyroidism and $9.75 \%$ with isolated hypothyroxinemia. According to the ATA reference range, $22.78 \%$ of our pregnant women had hypo- or hyperthyroidism and $6 \%$ had isolated hypothyroxinemia, while, by using our determined reference range, only $5.50 \%$ of pregnant women had thyroid dysfunction and none had isolated hypothyroxinemia. 
The strength of the present study was the measurement of TPOAb, urine iodine, and determination of thyroid gland size through ultrasound scanning. A combination of inclusion criteria, suggested by National Academy of Clinical Biochemistry (NACB) [43] and the National Health and National Examination Survey (NHANES) [44], were used to define the exclusion criteria. This resulted in a more clear definition of normal population for reference ranges. In addition, each participant was examined separately for thyroid gland scanning and full clinical examination was performed. A major limitation of this study was measuring UIC only once for each participant. Another limitation was the geographical restriction of sampling to the central area of Iran, which restrains the generalization of findings to the whole country.

\section{Conclusions}

In the present study, reference ranges of serum $\mathrm{TSH}, \mathrm{FT}_{4}$, and, $\mathrm{FT}_{3}$ concentrations were determined for singleton pregnant Iranian women with negative TPOAb (TSH: 0.2-4.60 mIU/l, FT 4 : 9.0$18.02 \mathrm{pmol} / \mathrm{l}$ and $\left.\mathrm{FT}_{3}: 3.40-5.64 \mathrm{pmol} / \mathrm{l}\right)$, and non-pregnant women (TSH: 0.59-5.60 mIU/l, $\mathrm{FT}_{4}$ : 9.52-19.30 pmol/l, and $\mathrm{FT}_{3}$ : 3.70$5.55 \mathrm{pmol} / \mathrm{l}$ ) with adequate level of iodine after being matched for age and gravidity. These values were different from the reference ranges, recommended by the ATA and the reference ranges, determined for non-pregnant women (TSH: $0.70-5.60 \mathrm{mIU} / \mathrm{I}$ vs. TSH: $0.35-5.50 \mathrm{mlU} / \mathrm{I}$ ) in our study. Therefore, we suggest the use of reference ranges obtained from this study for Iranian women, as recommended by guidelines.

\section{Authors' Contributions}

All authors were contributed to the design the study. A. A, A. H, and M. F supervised the findings of this work and M. K. and S. S. implementation of the research. A. F. and M. K. analyzed the data. A. A. and $M$. K. wrote the first draft of the manuscript. All authors reviewed and edited the manuscript and approved the final version of it. All authors are accountable for all aspects of the work. The datasets analyzed during the current study are available from the corresponding author on reasonable request.

\section{Acknowledgements}

The authors would like to express special thanks to all the pregnant and non-pregnant women who participated in the study. They also thank the Deputy of Health, the heads of the health centers, the obstetricians' gynecologists and midwives who cooperated with the researchers, Ms. A. Noroozi Bazaz, Ms. F. Hashmi, and Ms. S. Hajiapour, technical staffs of Isfahan Endocrine and Metabolism Research Center laboratory and Ms. A Haydari, Mr. A Haydarian and Mr. M. Sadaghi, technical staffs of the Deputy of Health laboratory.

\section{Funding}

The study was funded by the Endocrinology and Metabolism Research Center of Isfahan University of Medical Sciences in Isfahan, Iran; under the grant No. 394616. The authors declare that they have no competing financial interests.

\section{Conflict of Interest}

The authors declare that they have no conflict of interest.

\section{References}

[1] Moleti M, Trimarchi F, Vermiglio F. Thyroid Physiology in Pregnancy. Review Article. Endocr Pract 2014; 20: 589-596

[2] Yoshimura M, Hershman JM. Thyrotropic action of human chorionic gonadotropin. Thyroid 1995; 5: 425-434

[3] De Escobar GM, Obregón MJ, Del Rey FE. Role of thyroid hormone during early brain development. Eur J Endocrinol 2004; 151: (Suppl 3): U25-U37

[4] Fisher DA. Fetal thyroid function: Diagnosis and management of fetal thyroid disorders. Clin Obestet Gynecol 1997; 40: 16-31

[5] Medici M, Korevaar TI, Visser WE et al. Thyroid function in pregnancy: What is normal? Clin Chem 2015; 61: 704-713

[6] Lazarus JH, Bestwick JP, Channon S et al. Antenatal thyroid screening and childhood cognitive function. N Engl J Med 2012; 366: 493-501

[7] Lazarus JH. Thyroid function in pregnancy. Br Med Bull 2011; 97 : 137-148

[8] Delange F. lodine deficiency as a cause of brain damage. Postgrad Med J 2001; 77: 217-220

[9] Gilbert RM, Hadlow NC, Walsh JP et al. Assessment of thyroid function during pregnancy: First-trimester (weeks 9-13) reference intervals derived from Western Australian women. Med J Aust 2008; 189 : 250-253

[10] Lin L, Zhang XL, Long Y. Analysis of thyroid peroxidase antibody in early pregnancy. Genet Mol Res 2014; 13: 5107-5114

[11] Männistö T, Surcel HM, Ruokonen A et al. Early pregnancy reference intervals of thyroid hormone concentrations in a thyroid antibody-negative pregnant population. Thyroid 2011; 21: 291-298

[12] Berta E, Samson L, Lenkey A et al. Evaluation of the thyroid function of healthy pregnant women by five different hormone assays Pharmazie. Pharmazie 2010; 65: 436-439

[13] Wang QW, Yu B, Huang RP et al. Assessment of thyroid function during pregnancy: The advantage of self-sequential longitudinal reference intervals. Arch Med Sci 2011; 4: 679-684

[14] Khalid AS, Marchoki Z, Hayes K et al. Establishing trimester-specific maternal thyroid function reference intervals. Ann Clin Biochem 2014; 51: 277-283

[15] Alexander EK, Pearce EN, Brent GA et al. 2017 Guidelines of the American Thyroid Association for the diagnosis and management of thyroid disease during pregnancy and the postpartum. Thyroid 2017; 27: 315-389

[16] De Groot L, Abalovich M, Alexander EK et al. Management of thyroid dysfunction during pregnancy and postpartum: An Endocrine Society clinical practice guideline. J Clin Endocrinol Metab 2012; 97 : 2543-2565

[17] Lazarus J, Brown RS, Daumerie C et al. 2014 European thyroid association guidelines for the management of subclinical hypothyroidism in pregnancy and in children. Eur Thyroid J 2014; 3: 76-94

[18] Parvin CA, Gray DL, Kessler G. Influence of assay method differences on multiple of the median distributions: Maternal serum alpha-fetoprotein as an example. Clin Chem 1991; 37: 637-642

[19] Cunninghan FG, Leveno KJ, Bloom SL et al. Williams obstetrics. 23rd ed. New York: McGraw Hill Medical; 2010

[20] Khazan M, Yaghmaei P, Behdadfar L et al. Microwave digestion for urine iodine determination. Iran J Endocrinol Metab 2010; 12: 65-70 
[21] NAOES Morias, ASA Assis, Corcino CM et al. Recent recommendations from ATA guidelines to define the upper reference range for serum TSH in the first trimester match reference ranges for pregnant women in Rio de Janeiro. Arch Endocrinol Metab 2018; 62: 386-391

[22] Stricker R, Echenard M, Eberhart R et al. Evaluation of maternal thyroid function during pregnancy: The importance of using gestational age-specific reference intervals. Eur J Endocrinol 2007; 157: 509-514

[23] Sekhri T, Juhi JA, Wilfred $R$ et al. Trimester specific reference intervals for thyroid function tests in normal Indian pregnant women. Indian J Endocrinol Metab 2016; 20: 101-107

[24] Dhatt GS, Jayasundaram R, Wareth LA et al. Thyrotrophin and free thyroxine trimester-specific reference intervals in a mixed ethnic pregnant population in the United Arab Emirates Clinica Chimi Acta. 2006; 370: 147-151

[25] Korevaar TI, Medici M, de Rijke YB et al. Ethnic differences in maternal thyroid parameters during pregnancy: The generation r study. J Clin Endocrinol Metab 2013; 98: 3678-3686

[26] O’Brien JE, Dvorin E, Drugan A et al. Race-ethnicity-specific variation in multiple-marker biochemical screening: Alpha-fetoprotein, hCG, and estriol. Obstet Gynecol 1997; 89: 355-358

[27] McNeil AR, Stanford PE. Reporting thyroid function tests in pregnancy. Review article. Clin Biochem Rev 2015; 36: 109-126

[28] Karakosta P, ChatziL Bagkeris E et al. First- and second-trimester reference intervals for thyroid hormones during pregnancy in "rhea"mother-child cohort, crete, greece. J Thyroid Res 2011; 2011 490783

[29] Mehran L, Amouzegar A, Delshad H et al. Trimester-specific reference ranges for thyroid hormones in iranian pregnant women. J Thyroid Res 2013 Article ID 651517

[30] Azizi F, Mehran L, Amouzegar A et al. Establishment of the trimester-specific reference range for free thyroxine index. Thyroid 2013; 23: 354-359

[31] Pearce EN, Oken E, Gillman MW et al. Association of first-trisemester thyroid function test values with thyroperoxidase antibody status, smoking, and multivitamin use. Endocr Pract 2008; 14: 33-39

[32] Lepoutre T, Debiéve DF, Gruson D et al. Reduction of miscarriages through universal screening and treatment of thyroid autoimmune diseases. Gynecol Obstet Invest 2012; 74: 265-273

[33] Pekonen F, Alfthan H, Stenman UH et al. Human chorionic gonadotropin (hCG) and thyroid function in early human pregnancy: circadian variation and evidence for intrinsic thyrotropic activity of hCG. J Clin Endocrinol Metab 1988; 66: 853-856
[34] Marwaha RK, Chopra S, Gopalakrishnan S et al. Establishment of reference range for thyroid hormones in normal pregnant Indian women. BJOG 2008; 115: 602-606

[35] Li C, Shan Z, Mao J et al. Assessment of thyroid function during first-trimester pregnancy: what is the rational upper limit of serum TSH during the first trimester in Chinese pregnant women? J Clin Endocrinol Metab 2014; 99: 73-79

[36] Moon H-W, Chung H-J, Park C-M et al. Establishment of Trimester-Specific Reference Intervals for Thyroid Hormones in Korean Pregnant Women. Ann Lab Med 2015; 35: 198-204

[37] Yan YQ, Dong ZL, Dong L et al. Trimester- and method-specific reference intervals for thyroid tests in pregnant Chinese women: Methodology, euthyroid definition and iodine status can influence the setting of reference intervals. Clin Endocrinol 2011; 74: 262-269

[38] Xing J, Yuan E, Li J et al. Trimester-and assay-specific thyroid reference intervals for pregnant women in China. Int J Endocrinol 2016; 2016 3754213

[39] Bestwick JP, John R, Maina A et al. Thyroid stimulating hormone and free thyroxine in pregnancy: expressing concentrations as multiples of the median (MoMs). Clin Chim Acta 2014; 430: 33-37

[40] Medici M, de Rijke YB, Peeters RP et al. Maternal Early preganacy and newborn thyroid hormone parameters:The Generation R study. J Clin Endocrinol Metab 2012; 97: 646-652

[41] Dashe JS, Casey BM, CB Wells CE et al. Thyroid-stimulating hormone in singletonand twin pregnancy: importance of gestational age-specific reference ranges. Obstet Gynecol 2005; 106: 753-757

[42] Bishop JC, Dunstan F, Nix B] et al. All MoMs are not equal: Some statistical properties associated with reporting results in the form of multiples of the median. Am J Human Genet 1993; 52: 425

[43] Baloch Z, Carayon P, Conte-Devolx B et al. Laboratory medicine practice guidelines. Laboratory support for the diagnosis and monitoring of thyroid disease. Thyroid 2003; 13: 3

[44] Hollowell JG, Staehling NW, Flanders WD et al. Serum TSH, T4, and thyroid antibodies in the United States population (1988 to 1994): National Health and Nutrition Examination Survey (NHANES III). J Clin Endocrinol Metab. 2002: 87: 489-499

\section{Notice}

This article was changed according to the erratum on August 12, 2021.

\section{Erratum}

In the above-mentioned article Fig. 1, Tables 1, 2 and 3 were incorrect. This has now been corrected. 